\title{
Current and novel drug therapies for idiopathic pulmonary fibrosis
}

This article was published in the following Dove Press journal:

Drug Design, Development and Therapy

25 September 2012

Number of times this article has been viewed

\author{
Huzaifa I Adamali' \\ Toby M Maher ${ }^{1-3}$ \\ 'Interstitial Lung Disease Unit, Royal \\ Brompton Hospital, London, UK; \\ ${ }^{2}$ National Heart and Lung Institute, \\ Imperial College London, \\ London, UK; ${ }^{3}$ Centre for Respiratory \\ Research, University College London, \\ London, UK
}

\begin{abstract}
Over the past decade, there has been a cohesive effort from patients, physicians, clinical and basic scientists, and the pharmaceutical industry to find definitive treatments for idiopathic pulmonary fibrosis (IPF). As understanding of disease behavior and pathogenesis has improved, the aims of those treating IPF have shifted from reversing the disease to slowing or preventing progression of this chronic fibrotic illness. It is to be hoped that by slowing disease progression, survival will be improved from the current dismal median of 3.5 years following diagnosis. In Europe and Asia, a milestone has recently been reached with the licensing of the first IPF-specific drug, pirfenidone. This review assesses the current treatment modalities available for IPF, including pirfenidone. It also turns an eye to the future and discusses the growing number of promising compounds currently in development that it is hoped, in time, will make their way into the clinic as treatments for IPF.
\end{abstract}

Keywords: interstitial lung disease, pirfenidone, clinical trials, usual interstitial pneumonia, acute exacerbations

\section{Introduction}

Idiopathic pulmonary fibrosis (IPF) is a relentlessly progressive scarring disorder of the lungs characterized by dyspnea, cough, and ultimately respiratory failure. The disease has a median age at diagnosis of 66 years, and shows a male predominance. The prevalence of IPF is estimated at between 14 and 42.7 per $100,000 .^{1,2}$ The incidence of IPF is 6.8 to 16.3 per 100,000 , and this figure has been rising decade after decade for the last 30 years. ${ }^{3}$ As such, IPF now accounts for over 4000 deaths annually in the United Kingdom. With a median survival from diagnosis of 2.8-4.2 years and a 5-year survival approaching $20 \%$, IPF is more lethal than many cancers.

The rising incidence and poor prognosis of IPF has resulted in the discovery of new therapies becoming an increasing priority for the academic community and the pharmaceutical industry. The last decade has seen a huge rise in clinical trial activity in IPF. While these trials have produced a number of negative results, they have also led to the recent licensing in Europe and Asia of the first drug developed specifically for the treatment of IPF, pirfenidone (InterMune Inc, Brisbane, CA). This review will discuss the data underpinning the use of pirfenidone as a treatment for IPF and will assess the evidence supporting the growing number of compounds, all in varying phases of development, which may in the future revolutionize the treatment of this devastating condition.
Correspondence: Toby M Maher Interstitial Lung Disease Unit, Royal Brompton Hospital, Sydney Street, London SW3 6NP, UK

Tel +4420735I 8018

Fax +4420735I 895I

Email t.maher@rbht.nhs.uk 


\section{The challenge of treating IPF}

The histological correlate of IPF, usual interstitial pneumonia (UIP), is characterized by spatially and temporally heterogeneous fibrosis, with honeycombing and the presence of fibroblastic foci. The fibrosis in UIP/IPF results in marked architectural distortion and destruction of the lung with loss of alveolar spaces. The nature of the destruction wrought on the lung by UIP is such that even if a therapy were capable of reversing fibrosis, it would not restore normal lung structure or function. With this in mind, the aim of treatment in IPF is not to improve lung function or reduce symptoms, but is instead targeted at reducing or ideally preventing further disease progression. This approach to treatment requires a paradigm shift in the expectations of both patients and their physicians. Stability in lung function with therapy should be viewed a considerable success and not as failure, as is often the case. It is to be hoped that stabilization of lung function will result in improved survival for individuals with the disease.

Current approaches to managing and monitoring individuals with IPF have been greatly informed by observations made in clinical trials. ${ }^{4}$ The first multicenter randomized control trial in IPF was published as recently as $2004 .^{5}$ Since then however, there has been an exponential increase in the numbers of subjects enrolling in IPF clinical trials worldwide. At the same time, there has been a quiet evolution in the choice and interpretation of end-points in these studies. Change in the rate of decline of forced vital capacity (FVC) has now come to be accepted as the primary end-point of choice in current IPF clinical trials, and is viewed by many as a surrogate, albeit unproven, for survival. Given that IPF is a disease causing considerable morbidity and mortality, it has been increasingly recognized that therapies that improve symptoms without necessarily improving survival are also of value in the management of the condition. There is therefore an increasing focus on measures of quality of life and health-care utilization as surrogate end-points for reduced morbidity.

Despite the growth in clinical trials for IPF, the rate of change in clinical practice has been much slower. A number of compounds, many of which showed early promise, include interferon- $\gamma$, endothelin antagonists, the tyrosine kinase inhibitor imatinib, the antitumor necrosis factor (TNF)- $\alpha$ monoclonal antibody etanercept, and warfarin, have all been effectively discounted as potential therapies for IPF. ${ }^{6-9}$ Furthermore, the combination of high-dose corticosteroids and the immunosuppressant azathioprine (treatment that was recommended by international guidelines ${ }^{10}$ that remained current until 2011 $)^{11}$ has been shown in the recently published National Institutes of Health-sponsored PANTHER-IPF study to be potentially deleterious for individuals with IPF. ${ }^{12}$ Notwithstanding these setbacks, there have been a number of important developments for individuals with IPF. Foremost amongst these is the licensing of pirfenidone, a novel, first in-class, antifibrotic agent in Europe and Asia.

\section{An approach to the treatment of IPF}

Clinically, IPF is characterized by the development of progressive exertional dyspnea that almost inevitably results in respiratory failure. In a significant proportion of individuals, dyspnea is associated with a troublesome cough. As well as respiratory failure, IPF also gives rise to a number of diseaserelated complications. These include acute exacerbations (unheralded episodes of rapid disease progression occurring in the absence of infection), recurrent infection, pulmonary hypertension, and a markedly increased incidence of lung cancer. When approaching the management of individuals with IPF, clinicians have three potential goals: (1) to prevent or at least slow disease progression through the use of antifibrotic therapies, (2) the alleviation of symptoms, and (3) the identification and treatment of disease-specific complications. This review will focus specifically on the pharmacological interventions that can or may in the future be used to achieve the first of these goals.

\section{Pirfenidone}

Pirfenidone (5-methyl-1-phenyl-2-[1H]-pyridone) is a pleiotropic molecule that has antifibrotic, anti-inflammatory and antioxidant effects. ${ }^{13}$ In vitro pirfenidone inhibits transforming growth factor (TGF)- $\beta$-stimulated collagen synthesis, decreases synthesis by fibroblasts of extracellular matrix proteins, and blocks the proliferative effects of plateletderived growth factor (PDGF) on fibroblasts isolated from IPF lung. ${ }^{14-16}$ In animal models of pulmonary fibrosis, pirfenidone attenuates a range of profibrotic mediators while downregulating histological markers of cellular proliferation. ${ }^{15-17}$

The first large-scale trial of pirfenidone was a Japanese multicenter randomized placebo-controlled Phase II study of 107 subjects who received either pirfenidone $600 \mathrm{mg}$ three times daily $(n=72)$ or placebo $(n=35) .{ }^{18}$ The primary end point of the study was change in lowest arterial oxygen saturation measured by pulse oximetry during a 6 -minute walk (6MW). The trial was designed to run for 1 year; however, 9-month interim results revealed that five subjects in the placebo group had suffered acute exacerbations, compared 
to none in the pirfenidone group $(P<0.0031)$. The study's data and safety monitoring board (DSMB) therefore recommended early termination of the study on ethical grounds and advised the initiation of pirfenidone in the placebo group. The primary end-point was not achieved; however, there was a significant attenuation in decline of FVC in the pirfenidone group when compared to the placebo group. At the time of the trial, there was no consensus on the most appropriate end-point to use for the therapeutic effect of IPF. In light of the difficulty of interpreting the primary end-point in this trial, the utilization of lowest saturation in a steady-exercise test has been abandoned in subsequent trials.

The trial by Azuma et $\mathrm{al}^{18}$ led to the development of a Japanese multicenter double-blind placebo-controlled randomized phase III clinical trial conducted over 52 weeks. ${ }^{19}$ A total of 275 patients were randomized to either high(1800 mg/day) or low-dose (1200 mg/day) pirfenidone or placebo in the ratio 2:1:2. Significant differences were observed in FVC decline (primary end-point) between the placebo group $(-0.16 \mathrm{~L})$ and the high-dose group $(-0.09 \mathrm{~L})(P<0.0416)$. Among the secondary end-points, the progression-free survival time (with disease progression defined as more than 10\% decrease in FVC and/or death) was significantly prolonged in the high-dose group compared to the placebo group $(P<0.0280)$. The study has been criticized because the primary end-point was changed after completion of the study but prior to unbinding, and because of the statistical methods used to handle missing values (last observation carried forward).

The CAPACITY trials consisted of two concurrent multi-national randomized double-blind placebo-controlled phase III trials (004 and 006), designed to evaluate the safety and efficacy of pirfenidone in IPF patients with mild to moderate impairment in lung function (FVC $\geq 50 \%$ of predicted values and a diffusing capacity $\left[\mathrm{DL}_{\mathrm{CO}}\right] \geq 35 \%$ of predicted value). ${ }^{20}$ In study 004,174 patients were assigned to high-dose pirfenidone ( $2403 \mathrm{mg} /$ day), 87 patients to lowdose pirfenidone (1197 mg/day), and 174 to placebo. In study 006, 171 patients were assigned to high-dose pirfenidone (2403 mg/day), and 173 patients to placebo. The primary endpoint of both CAPACITY studies was change in percentage predicted FVC after 72 weeks of treatment. The trials were not powered to assess survival.

In study 004, the higher dose of pirfenidone met the primary end-point, significantly decreasing the fall in FVC at week 72 (difference between groups of $4.4 \%, P=0.001$ ). By contrast, study 006 failed to meet the primary end-point (FVC difference between groups of $0.6 \%, P=0.501$ ).
However, in 006 pirfenidone did significantly reduce decline in the secondary end-point of 6MWT distance (absolute difference of 32 meters, $P=0.0009$ ). The reason for the different outcomes in the two studies remains unclear. Of note, however, is the observation that while the rate of decline in FVC in the pirfenidone group was the same in both studies, the individuals in the 006 placebo group had a slower rate of decline compared to those in 004.

A recent Cochrane review ${ }^{21}$ encompassing the two Japanese trials and CAPACITY 004 and 006 has shown that across the four studies pirfenidone improved progressionfree survival by $30 \%$ (hazard ratio $0.70,95 \%$ confidence interval 0.56-0.88). In light of these studies, the European Medicines Agency approved the use of pirfenidone based on CAPACITY 004 and the Japanese phase III trial. However, in the US the FDA declined to approve the medication, given the failure of 006 to meet its primary end-point. As a result, a phase III study (the ASCEND trial, NCT0136629) spanning 52 weeks is currently under way in the US. Pirfenidone has also been licensed for use in Japan and India.

\section{Dosing and side effect profile}

In Europe, the recommended dosage of pirfenidone is $2403 \mathrm{mg} /$ day, delivered in three divided doses. The most common reported side effects for pirfenidone are gastrointestinal symptoms and photosensitivity. ${ }^{18-20,22}$ Hepatic dysfunction has been noted, with rises in aspartate transaminase and alanine transaminase, ${ }^{18-20}$ which in clinical trials has always been reversible following pirfenidone cessation. Administration of pirfenidone after meals has been shown to reduce gastrointestinal side effects. Limiting exposure to sunlight and using sunblock minimizes the risk of photosensitive reactions. The manufacturers of pirfenidone recommend that blood tests of liver function should be monitored prior to commencement of therapy, monthly for the first 6 months, and then every 3 months thereafter.

\section{$\mathbf{N}$-acetylcysteine}

A number of studies in in vitro and in vivo animal models of fibrosis and in human disease point toward reactive oxygen species being key players in the establishment and progression of pulmonary fibrosis. There is evidence of disruption of the normal oxidant/antioxidant balance in the lungs of IPF patients. ${ }^{23}$ The lungs of individuals with IPF show deficiency of key antioxidants, including glutathione and superoxide dismutase proteins, when compared to healthy individuals. ${ }^{24}$

$N$-acetylcysteine (NAC), a tripeptide ( $\gamma$-glutamylcysteinyl-glycine) precursor of the antioxidant glutathione, 
acts as a scavenger of oxygen free radicals. ${ }^{25}$ Interestingly, increasing glutathione levels with NAC inhibits growth of artery endothelial cells induced by TGF- $\beta .{ }^{26}$ Furthermore, NAC can directly alter the structure of TGF- $\beta,{ }^{27}$ thus attenuating the profibrotic properties of TGF- $\beta .{ }^{28} \mathrm{NAC}$ has also been shown to increase bronchoalveolar lavage (BAL) glutathione levels in the BAL fluid. ${ }^{29}$

A pilot proof-of-concept study of 12 weeks' duration ${ }^{30}$ demonstrated that oral NAC significantly increased BAL levels of glutathione and decreased the oxidative stress marker methionine sulfoxide. This pilot study led to the development of the IFIGENIA study. This was a doubleblind, randomized, multicenter study that assessed the effectiveness over 1 year of high-dose oral NAC (600 mg three times daily) together with prednisone and azathioprine compared to prednisone and azathioprine alone. ${ }^{31}$ The primary end point was change in $\mathrm{FVC}$ and $\mathrm{DL}_{\mathrm{CO}}$. At 12 months, NAC significantly slowed the deterioration of FVC by $9 \%$. The lack of a true placebo arm in the study led many to question whether triple therapy offers genuine benefit to patients compared with no treatment. Consequently, the PANTHER-IPF study was designed to evaluate whether the combination of prednisone, azathioprine, and NAC could slow disease progression and improve lung function in people with moderate IPF. ${ }^{12}$ Interim results showed that compared to both placebo and NAC alone, those randomized to the tripletherapy regimen had greater mortality (11\% versus $1 \%)$, more hospitalizations ( $29 \%$ versus $8 \%$ ), and more serious adverse events (31\% versus $9 \%$ ), with no difference in lung function. As a result, the DSMB recommended terminating the triple-therapy arm of the study. The DSMB has not found any safety issues with NAC or placebo and has recommended that these arms of the trial continue to recruit participants, facilitating an analysis of the benefits and safety of NAC over placebo once the study is completed. ${ }^{12}$

\section{Lung transplantation}

While lung transplantation is currently the only treatment available for IPF that has been shown to improve survival, the benefits of treatment need to be carefully balanced against the many downsides of transplantation. These downsides include the limited availability of donor organs, the ever-present risk of both infection and rejection, and the lifelong need for immunosuppressant therapy. In the UK, IPF accounts for $20 \%$ of all lung transplants; ${ }^{32}$ however, individuals with IPF have the highest death rate for all diagnostic groups on the transplant waiting list. ${ }^{32,33}$ The 5-year survival rate following lung transplantation for IPF is similar to other disease groups and stands at $45 \%-50 \% .^{32,34}$ Timing of referral for transplant is frequently challenging; however, criteria to address this have been produced by the International Society for Heart and Lung Transplant. ${ }^{33}$ The society's guidelines recommend that individuals with IPF should be considered for transplantation if their $\mathrm{DL}_{\mathrm{CO}}$ is $<40 \%$ of predicted, if they have suffered a decrement in FVC $>10 \%$ during the preceding 6 months, or if they show a decrease in pulse oximetry $<88 \%$ saturation during a $6 \mathrm{MW}$.

\section{Acute exacerbations}

An acute exacerbation (AE) of IPF has been defined as an unexpected, accelerated phase of symptomatic decline occurring in the absence of infection, pulmonary embolism, pneumothorax, heart failure, or any other identifiable cause of acute lung injury. ${ }^{35-37}$ In clinical trials, AEs have been observed in $5 \%-8 \%$ of individuals with IPF per year. ${ }^{18,38,39}$ The in-hospital mortality associated with AEs is as high as $50 \%{ }^{39}$ An ATS/ERS consensus group proposed the following diagnostic criteria for an AE-IPF: (1) worsening of dyspnea within 30 days, (2) severe decrease of $\mathrm{PaO}_{2}$ in arterial blood, (3) absence of pulmonary infection by endotracheal aspirate or BAL, and (4) radiographic findings of bilateral ground-glass opacities and consolidation superimposed on a pattern typical of usual interstitial pneumonia on high-resolution computed tomography. ${ }^{37}$ On biopsy, AE-IPF shows a lesion of diffuse alveolar damage or organizing pneumonia on a background of UIP. ${ }^{40}$

There is no consensus regarding the treatment of patients suffering an AE. Even though there is a lack of data validating efficacy, most centers empirically treat patients with broad-spectrum antibiotics and pulsed doses of methylprednisolone (1-2 g per day) or high-dose oral glucocorticoids (prednisolone $1 \mathrm{mg} / \mathrm{kg}$ per day orally).,37 Cytotoxic agents including azathioprine, cyclosporin A, and cyclophosphamide have been studied, but no convincing evidence of benefit has been demonstrated.

In AEs, it has been shown that a prothrombotic milieu, generated by abundant neointimal tissue factors and endothelial injury, exists in the lungs. ${ }^{36,41}$ In keeping with this observation, an increased incidence of death due to thromboembolic disease has been documented in IPF. ${ }^{35}$ A Japanese study published in 2005 noted that anticoagulant therapy (with low-molecular-weight heparin for hospitalized patients and warfarin for those in a domiciliary setting) in combination with prednisolone therapy showed an improved overall survival at 3 years and reduced mortality associated with acute exacerbation (63\% vs 35\%) compared with patients receiving prednisolone alone. ${ }^{38}$ However, the study 
has been criticized for lack of blinding, failure to account for differential dropout of $25 \%$ in the treatment group in further intention-to-treat analysis, and lack of clarity concerning case definition and inclusion criteria. The ACE-IPF trial, a phase III, randomized, double-blind, placebo-controlled study of warfarin as a treatment for IPF (NCT00957242), was suspended by the recommendation of the DSMB due to excess side effects and mortality in the warfarin arm, thus making the benefit unlikely. ${ }^{6}$ Warfarin should therefore only be used in IPF patients for whom there exists an alternative indication (eg, documented thromboembolic disease).

\section{Gastroesophageal reflux disease}

The presence of gastroesophageal reflux (GERD) in IPF patients has been documented in multiple studies. It is notable that almost half of patients with IPF and GERD are asymptomatic. ${ }^{42,43}$ A growing body of evidence suggests that chronic tracheobronchial aspiration of gastric contents over long periods of time may contribute to the progression of IPF. Both acute and chronic animal models ${ }^{44-47}$ of gastric fluid aspiration result in a profibrotic environment developing in the lungs, via production of TGF- $\beta$ and TNF- $\alpha$ with increased expression of collagen III/IV and fibronectin. ${ }^{48}$ In vitro studies using human epithelial cells have shown that bile salts increase TGF- $\beta$ production via a $\mathrm{p} 38$-MAP kinase-dependent pathway and that they also induce fibroblast proliferation. ${ }^{49}$

In an elegant retrospective study, a relationship was observed between disease severity, GERD, sleeping position, and acute exacerbations of IPF pathogenesis in IPF patients with asymmetric disease. ${ }^{50} \mathrm{~A}$ retrospective study showed that treatment of GERD was associated with lower radiological fibrosis scores on high-resolution computed tomography and was an independent predictor of longer survival time. ${ }^{51}$ Two retrospective case series showed stabilization of pulmonary function and oxygen requirements with medical and surgical management of GERD. ${ }^{52,53}$ While prospective studies are required to validate these findings, the available evidence suggests that individuals with IPF and demonstrable GERD should be commenced on appropriate antireflux therapy.

\section{Promising future therapies}

The last decade has seen dramatic strides being made in the understanding of the molecular pathogenesis of IPF. Insights gained from preclinical studies are now beginning to translate into therapies targeted at specific key pathways involved in the development and progression of fibrosis. A number of novel molecules have begun to enter early phase clinical trials, and with luck, it is to be hoped that some of these may begin to appear in the clinic in the next few years. ${ }^{54}$ Some of the more promising approaches to the treatment of IPF are summarized in Figure 1 and are discussed in greater detail in the remainder of this manuscript.

\section{Tyrosine receptor kinase inhibitors}

Phosphorylation represents the most common form of posttranslational protein modification. Protein function can be altered by the addition of a negatively charged phosphate group to a serine, threonine, or tyrosine amino acid residue. Tyrosine kinases are a group of enzymes responsible for phosphorylation of tyrosine residues. They exert their effects at various levels in the signal-transduction pathway. ${ }^{55}$ Receptor tyrosine kinase (RTKs) may exist as single-unit receptors or as multimeric complexes. They are transmembrane proteins with extracellular ligand-binding domain, a transmembrane domain, and an intracellular tyrosine kinase domain. At present, 58 RTKs have been identified and they have been grouped into 20 subfamilies. ${ }^{56}$ Binding by ligands results in dimerization, autophosphorylation, and a cascade of down-

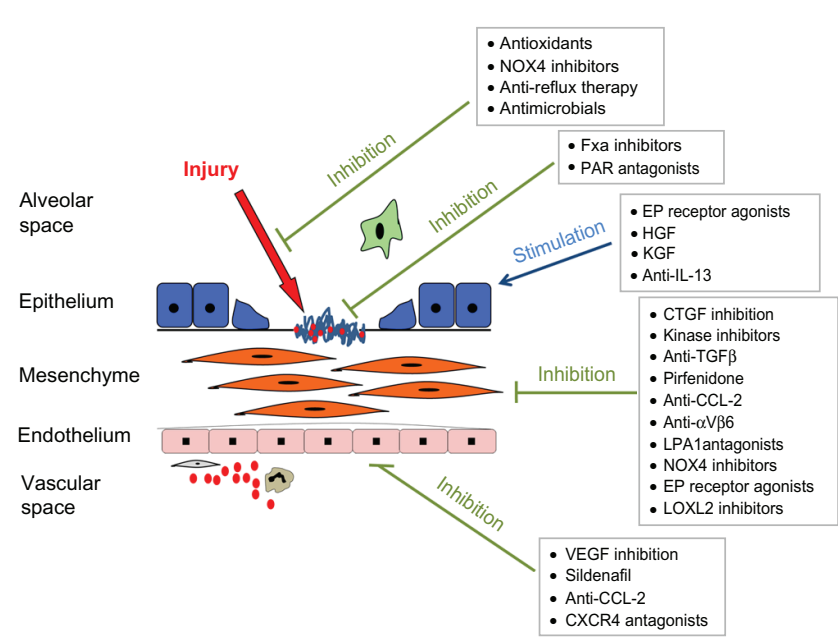

Figure I Current understanding of the pathogenesis of idiopathic pulmonary fibrosis (IPF) suggests that repetitive alveolar epithelial injury results in basement membrane denudation and activation of key pathways involved in the wound-healing response. Notes: This in turn leads to fibroblast proliferation, transformation of fibroblasts to myofibroblasts, and expansion of the extracellular matrix. These effects are augmented by the influx of circulating inflammatory cells, including the putative bone marrow-derived fibroblast precursor - the fibrocyte. Various treatments are in development targeting different aspects of IPF disease pathogenesis through inhibition of fibrogenesis, promotion of antifibrotic pathways, or reduction of alveolar injury. Copyright $^{\odot}$ 2012. Reprinted with permission from Elsevier. Maher TM. Idiopathic pulmonary fibrosis: pathobiology of novel approaches to treatment. Clin Chest Med. 2012;33:69-83. ${ }^{54}$

Abbreviations: $\mathrm{FXa}$, factor Xa; PAR, protease-activated receptor; HGF, hepatocyte growth factor; KGF, keratinocyte growth factor; IL, interleukin; TGF, transforming growth factor; CTGF, connective tissue growth factor; VEGF, vascular endothelial growth factor; NOX4, NADPH Oxidase 4. EP, E prostanoid; LPA, Lysophosphatidic acid; CCL-2, Chemokine (C-C motif) ligand 2. 
stream cellular effects that result in changes in gene expression, cell growth, metabolism, differentiation, and apoptosis.

Ligands for RTKs, including TGF- $\beta$, PDGF-B, connective tissue growth factor, fibroblast growth factor, and vascular endothelial growth factor, have been implicated in driving lung fibrosis. On this basis, investigators have developed selective tyrosine kinase inhibitors that target key fibrogenic pathways. Imanitib mesylate, a tyrosine kinase inhibitor with activity against PDGF receptors, c-kit, and c-ABL tyrosine kinases, was originally developed for the treatment of chronic myelogenous leukemia. Imanitib was shown to protect against fibrosis in rodent models of lung injury. ${ }^{56-58}$ However, in a placebocontrolled phase II trial that included mild to moderate IPF patients, imatinib showed no effect on the primary end point of progression-free survival (defined by a $10 \%$ decline in percent predicted FVC or survival over a 96-week period). ${ }^{59}$

BIBF 1120 is an inhibitor of PDGF, vascular endothelial growth-factor, and fibroblast growth-factor receptors, all of which have been implicated in the development of fibrosis. ${ }^{60}$ Inhibition of these receptors has been shown to prevent lung fibrosis in a bleomycin-induced rat lung fibrosis model. ${ }^{61}$ BIBF 1120 was assessed in the phase II TOMORROW trial. ${ }^{62}$ A total of 432 patients were assigned to four different doses of BIBF 1120 or placebo. The highest dose (150 mg twice daily) reduced the decline in FVC (0.06 L/year vs 0.19 L/year in the placebo group), reduced the rate of acute exacerbations, and improved quality of life. The highest dose of BIBF 1120 was associated with moderate gastrointestinal side effects and hepatoxicity. This molecule is now being assessed in parallel phase III trials (NCT 01335464 and NCT01335477).

\section{Anti-IL-I 3}

Interleukin (IL)-13 is a potent stimulator of fibroblast proliferation and extracellular matrix synthesis. ${ }^{63,64} \mathrm{IL}-13$ induces profibrotic cytokines, including TGF- $\beta$, PDGF, insulin-like growth factor 1, matrix metallopeptidase 9, chemokine (C-C motif) ligand (CCL) 18, connective tissue growth factor collagen 1 , and fibronectin production. Increased levels of IL-13 have been noted in BAL from IPF patients. ${ }^{65}$ Overexpression of IL-13 in mice induces lung fibrosis, ${ }^{66}$ while immunoneutralization of IL-13 in bleomycin-induced lung injury attenuates lung fibrosis. ${ }^{67}$ QAX576, a human monoclonal antibody against IL-13, is currently being tested in a multicenter phase II, randomized, double-blind, placebo-controlled study (NCT01266135).

\section{Anti-CCL2}

CCL2, also known as monocyte chemotactic protein 1, displays chemotactic activity for monocytes, basophils, $\mathrm{T}$ cells, immature dendritic cells, ${ }^{68}$ and fibrocytes. ${ }^{69}$ CCL2 is elevated in the BAL of IPF patients. ${ }^{70} \mathrm{CCR} 2$ (the murine homologue of CCL2) knockout mice are protected from fluorescein isothiocyanate-induced pulmonary fibrosis. ${ }^{71}$ In pulmonary fibroblasts, CCL2 signaling promotes the expression of the profibrotic cytokine TGF- $\beta .^{72} \mathrm{CNTO}-888$, an anti-CCL2 antibody, is being studied in a randomized doubleblinded placebo-controlled phase II trial (NCT00786201).

\section{Anti-TGF- $\beta$}

A profibrotic cytokine par excellence, TGF- $\beta$ exists in three isoforms - TGF- $\beta 1$, TGF- $\beta 2$, and TGF- $\beta 3$ - and is produced by most cells in the lung. TGF- $\beta 1$ has been implicated in the pathogenesis of pulmonary fibrosis. ${ }^{73}$ It has been localized in fibroblasts/myofibroblasts and within extracellular matrix of fibroblastic foci and areas of dense fibrous connective tissue. ${ }^{74-76}$ TGF- $\beta$ has multiple functions: ${ }^{77}$ it promotes chemotaxis and proliferation of fibroblasts, ${ }^{78}$ differentiation of fibroblasts into myofibroblasts, ${ }^{79}$ transformation of epithelial cells into myofibroblasts (epithelial-mesenchymal transition), ${ }^{80}$ and it protects myofibroblasts from apoptosis. ${ }^{81}$ In turn, myofibroblasts, an important source of extracellular matrix, further produce TGF- $\beta 1$ and perpetuate the fibrotic response. ${ }^{82}$ TGF- $\beta$ promotes the production of a range of profibrotic cytokines (TNF- $\alpha$, PDGF) and tissue inhibitors of metalloproteinases and inhibits matrix-degrading proteases. $^{83,84}$

The homeostatic role of $\mathrm{TGF}-\beta$ includes regulating the inflammatory response and involvement in tumorsuppression pathways. Targeting TGF- $\beta$ is a potential means of attenuating the fibrosis; however, complete inhibition of TGF- $\beta$ could potentially, as seen in the TGF- $\beta 1$ null mutation mouse model, lead to excessive inflammation and early death. ${ }^{85}$ TGF- $\beta 1$ 's homeostatic role may be adversely affected by inhibitory strategies, and in IPF patients, for whom there is an increased risk of developing lung cancer, this may be further potentiated. For this reason, a variety of strategies other than direct blockade of TGF- $\beta$ have been considered.

TGF- $\beta 1$ is secreted with a latency-associated protein that prevents it binding to TGF- $\beta$ receptors. ${ }^{86}$ The integrin, $\alpha v \beta 6$ activates TGF $\beta$ by cleaving off the latency-associated protein. In the lung, $\alpha v \beta 6$ is expressed at a low level in normal epithelium and is upregulated after injury. ${ }^{87}$ It is also present in the activated epithelium of IPF. ${ }^{88}$ Mice that do not express the $\beta 6$ subunit cannot form the receptor and are protected from bleomycin-induced pulmonary fibrosis. ${ }^{89}$ Monoclonal antibody directed at this integrin prevents murine 
radiation-induced lung fibrosis. ${ }^{90}$ Partial inhibition of TGF$\beta$, without affecting its homeostatic role, using monoclonal antibodies has been shown to be effective in blocking murine fibrosis without exacerbating inflammation. ${ }^{88} \mathrm{~A}$ humanized monoclonal antibody against $\alpha v \beta 6$ (STX-100) is currently being assessed in a phase II randomized, double-blind, placebo-controlled, multiple-dose, dose-escalation study in patients with IPF (NCT 01371035).

Binding of active TGF- $\beta 1$ to type II TGF transmembrane receptors results in the recruitment of type I receptors that together form a tetrameric complex. ${ }^{73}$ Receptor activation then occurs via phosphorylation of this tetrameric complex by activin receptor-like kinase 5 (ALK-5), which in turn leads to activation via phosphorylation of intracellular SMADs. These SMADs then migrate to the nucleus and initiate or inhibit the transcription of TGF- $\beta$-regulated genes. ${ }^{73}$ An ALK-5 inhibitor (SD-208) has been shown to inhibit the induction of fibrosis adenovirus TGF- $\beta 1$ transfection rat models of progressive fibrosis. ${ }^{91}$ In mice models of bleomycin-induced fibrosis, the oral ALK-5 inhibitor SB-525334 attenuates the progression of pulmonary fibrosis. ${ }^{92}$ Thus far, the use of ALK-5 inhibitors has been limited by potential cardiac toxicity.

\section{Lysyl oxidase-like protein}

The lysyl oxidases (LOX) are a group of enzymes that catalyze the oxidative deamination reaction between a lysyl or a hydroxylysyl residue, thus facilitating the cross-linking of type 1 collagen molecules. ${ }^{93,94}$ Although the alignment of collagen molecules into their specific supramolecular organization occurs spontaneously, these fiber structures do not attain the necessary tensile strength until the molecules have been covalently linked together by specific intra- and intermolecular cross-links, and this is facilitated by LOX. Five additional LOX-like (LOXL) enzymes have been implicated in a variety of disease processes. LOXL 2 has been reported to enhance the in vivo accumulation and deposition of collagen in breast tumors and glioma tumors formed by LOXL2 overexpressing cancer cells. ${ }^{95,96}$ LOXL2 levels have been noted to be upregulated in $\mathrm{IPF}^{96}$ and in other fibrotic diseases, including fibrotic liver disease. ${ }^{97}$ Increased LOXL2 expression is observed in fibroblasts during replicative- and stress-induced premature senescence ${ }^{98,99}$ and also plays a role in promoting cell proliferation. ${ }^{95,97}$ In the murine bleomycininduced lung fibrosis model, LOXL2 upregulation is attenuated by an anti-LOXL2 monoclonal antibody (AB0024), with a reduction seen in fibrillar collagen, activated fibroblasts, and inflammatory cytokines, including TGF- $\beta 1 .{ }^{96} \mathrm{AB} 0024$ is now entering early trials in IPF (NCT01362231).

\section{MicroRNA}

There is growing evidence that regulation of gene transcription is more complex than hitherto suspected. One mechanism of transcriptional regulation involves microRNAs (miRNA); these are small noncoding endogenous RNAs approximately 20-25 nucleotides long. It is estimated that up to one-third of the human genome may be subject to regulation by miRNAs. ${ }^{100}$ These molecules play a critical role in various physiological processes, including tissue development, differentiation, cellular proliferation, and tissue repair. ${ }^{101,102}$ Dysregulation of miRNAs may contribute to disease pathology ${ }^{103}$ and has been implicated in cancer, heart disease, diabetes, and inflammation. ${ }^{104}$

miRNAs negatively regulate gene expression at a posttranscriptional level ${ }^{105}$ directly by inducing mRNA degradation or translation inhibition and indirectly through global effects on methylation. ${ }^{106}$ Pandit et al examined miRNA levels in IPF and observed that let-7d, miR-26, and members of the miR-30 family were all decreased in IPF biopsies compared with normal biopsies. ${ }^{105}$ TGF- $\beta$ inhibits let-7d expression, thereby driving epithelial-mesenchymal transition and increasing collagen deposition. In vitro, inhibition of let-7d induces an increase in mesenchymal markers. In vivo inhibition of let-7 $d$ in mouse lungs causes alveolar septal thickening and increased expression of collagen. Liu et al noted an increase in the oncogenic miR-2 1 in both IPF patients and in the bleomycin-induced fibrotic mouse model. ${ }^{107}$ Enhanced miR-21 is observed in pulmonary fibroblasts treated with TGF- $\beta$. Inhibition of miR-21 using antisense probes attenuates fibrosis in murine bleomycin-induced fibrosis. miR-21 targets SMAD7 and reduces SMAD2 phosphorylation, causing an increase in TGF- $\beta$ signaling that promotes fibrosis. Cushing et al showed miR-29 levels are reduced in fibrotic lungs. ${ }^{108}$ This corresponded to an increase in collagens, laminins and integrins. Recently, Oak et al showed that miRNA profiling in surgical lung biopsies differentiated normal lungs from IPF and rapidly progressive IPF from slowly progressive IPF. ${ }^{109}$

miRNAs offer an interesting new avenue for therapeutic development, both in IPF and in a range of other diseases. Antagomirs, single-stranded nucleic acids that bind and inhibit endogenous miRNA, may be useful in inhibiting upregulated pathogenic miRNA. Similarly, replacement of downregulated miRNA may be an effective treatment strategy. ${ }^{110}$

\section{Antiviral therapy}

Multiple viruses have been implicated in the development of IPF, including Epstein-Barr virus (EBV), hepatitis C, 
human herpesvirus 7 and 8, cytomegalovirus (CMV), and parvovirus. It is postulated that that viruses can precipitate and worsen lung fibrosis by inducing alveolar endothelial cell injury, by triggering inflammation, and through the induction of proinflammatory cytokines ${ }^{112,113}$ and other profibrotic mediators. ${ }^{113-115} \mathrm{CMV}$ is a double-stranded DNA that belongs to the $\beta$-herpesvirus family. Yonemaru et al found $\mathrm{CMV}$ immunoglobulin $\mathrm{G}$ and complement-fixation titers were elevated in IPF patients $(n=43)$ compared to controls. ${ }^{116} \mathrm{CMV}$ immunoglobulin $\mathrm{M}$ was negative, suggesting that latent CMV infections may be prominent in IPF. Using polymerase chain reaction (PCR), Tang et al showed an increased prevalence of CMV in IPF patients. ${ }^{117}$ Using serological and molecular analysis (reverse-transcriptase PCR and solution PCR), CMV RNA was found in endothelium, pneumocytes, and alveolar macrophages in lung-biopsy material from IPF patients with serologic evidence of active or recent CMV infection. ${ }^{118}$

EBV, belonging to the Gammaherpesvirus subfamily, has also been implicated in IPF. Vergnon et al showed seropositivity to EBV in IPF patients. ${ }^{119}$ Using immunocytochemistry, Egan et al demonstrated EBV replication (viral caspid coat and gp 340/200) in 70\% of IPF patients' biopsies in contrast to $9 \%$ of control patients. ${ }^{120}$ The presence of EBV DNA was also confirmed in IPF biopsies ${ }^{117,121,122}$ and BAL. ${ }^{123}$

Animal studies suggest that EBV alone does not cause pulmonary fibrosis but may be a cofactor in disease progression or act as a source of injury in a predisposed host. ${ }^{124}$ EBV in lung epithelial cells has been reported to increase transcription of TGF- $\beta 1 .{ }^{114}$ EBV-infected cells express latent membrane protein (LMP-1). LMP-1 is a six-pass transmembrane protein that mimics a constitutively active member of the TNF-receptor superfamily, and activates, among others, the nuclear factor kappa $\mathrm{B}^{125}$ and extracellular signal-regulated kinase (ERK). ${ }^{126}$ In vitro data show that LMP-1 in epithelial cells synergizes with TGF- $\beta 1$ to induce epithelial-mesenchymal transformation. ${ }^{126}$ Activation of the ERK pathway was shown to be critical for aspects of TGF- $\beta 1-$ induced epithelial-mesenchymal transformation. LMP-1 accentuated the TGF- $\beta 1$ activation of ERK. Interestingly, LMP-1 positivity in the epithelium was associated with increased disease progression and poor prognosis in IPF patients. ${ }^{122}$ Together, these data demonstrate that the presence of LMP-1 in lung epithelial cells synergizes with TGF- $\beta 1$ to induce epithelial mesenchymal transformation and creates an environment for rapid progression of the illness.

Mora et al have developed a model of chronic herpesvirus-induced pulmonary fibrosis infection using murine herpesvirus 68, a natural pathogen of rodents that has a high homology to EBV. ${ }^{112}$ They explored this model in interferon- $\gamma$ receptor-deficient mice. This model results in marked impairment in the control of acute viral infections. The interferon- $\gamma$ receptor-deficient mice showed persistent lyric viral infection, inflammation, and pulmonary fibrosis. These authors further showed that antiviral therapy beginning 45-60 days after initial infection controlled virus replication during chronic infection and attenuated lung fibrosis. Vanella et al have shown that mice transfected with murine herpesvirus 68 following the development of bleomycin-induced pulmonary fibrosis develop diffuse alveolar damage analogous to that seen in acute exacerbations of IPF. ${ }^{124}$ In a small observational study, Egan et al used intravenous ganciclovir for 2 weeks in fourteen advanced IPF patients who had failed standard therapy. Nine patients showed an improvement in symptoms and 6MWT distance. Appropriate randomized studies are required before ganciclovir can be considered as a therapy for IPF. ${ }^{127}$

\section{Conclusion}

IPF is a devastating and progressive disease that has until recently lacked any effective therapies. In the past, symptom control and the treatment of disease-related complications have been the only therapeutic avenues open to clinicians and their patients. The licensing in Europe, India, and Japan of the novel antifibrotic agent pirfenidone therefore represents an important and exciting step forward in the management of IPF. However, pirfenidone slows but does not halt progression of disease in individuals with IPF. There remains, therefore, considerable scope for the development of further antifibrotic treatments with the hope that in the future it may become possible to arrest disease progression completely in individuals diagnosed with IPF. Improved understanding of the pathogenetic mechanisms underlying the development of fibrosis has resulted in a rapid expansion in the number of compounds entering early phase clinical trials for IPF. It is to be hoped that this influx of compounds will ultimately lead, over the course of the next decade, to improvements in the standard of care available to individuals with IPF.

\section{Disclosure}

Toby Maher is in receipt of an unrestricted academic industry grant from GSK. In the last 3 years, Maher has received advisory board or consultancy fees from Actelion, Boehringer Ingelheim, GSK, Respironics, and Sanofi-Aventis, and he 
has also received speaker's fees from UCB and AstraZeneca. Maher's institution has received an unrestricted educational grant from InterMune.

\section{References}

1. Olson AL, Swigris JJ, Lezotte DC, Norris JM, Wilson CG, Brown KK. Mortality from pulmonary fibrosis increased in the United States from 1992 to 2003. Am J Respir Crit Care Med. 2007;176:277-284.

2. Gribbin J, Hubbard RB, Le Jeune I, Smith CJ, West J, Tata LJ. Incidence and mortality of idiopathic pulmonary fibrosis and sarcoidosis in the UK. Thorax. 2006;61:980-985.

3. Navaratnam V, Fleming KM, West J, et al. The rising incidence of idiopathic pulmonary fibrosis in the UK. Thorax. 2011;66:462-467.

4. Maher TM. The diagnosis of idiopathic pulmonary fibrosis and its complications. Expert Opin Med Diagn. 2008;2:1317-1331.

5. Raghu G, Brown KK, Bradford WZ, et al. A placebo-controlled trial of interferon gamma- $1 \mathrm{~b}$ in patients with idiopathic pulmonary fibrosis. N Engl J Med. 2004;350:125-133.

6. Noth I, Anstrom KJ, Calvert SB, et al. A placebo-controlled randomized trial of warfarin in idiopathic pulmonary fibrosis. Am J Respir Crit Care Med. 2012;186:88-95.

7. Ziesche R, Hofbauer E, Wittmann K, Petkov V, Block LH. A preliminary study of long term treatment with interferon gamma- $1 \mathrm{~b}$ and low dose prednisolone in patients with idiopathic pulmonary fibrosis. N Engl J Med. 1999;341:1264-1269.

8. King TE Jr, Brown KK, Raghu G, et al. BUILD-3: a randomized, controlled trial of bosentan in idiopathic pulmonary fibrosis. Am $J$ Respir Crit Care Med. 2011;184:92-99.

9. Daniels CE, Lasky JA, Limper AH, Mieras K, Gabor E, Schroeder DR. Imatinib treatment for idiopathic pulmonary fibrosis: randomized placebo-controlled trial results. Am J Respir Crit Care Med. 2010;181: 604-610.

10. American Thoracic Society, European Respiratory Society. American Thoracic Society/European Respiratory Society International Multidisciplinary Consensus Classification of the Idiopathic Interstitial Pneumonias. This joint statement of the American Thoracic Society (ATS), and the European Respiratory Society (ERS) was adopted by the ATS board of directors, Jun 2001 and by the ERS Executive Committee, Jun 2001. Am J Respir Crit Care Med. 2002;165:277-304.

11. Raghu G, Collard HR, Egan JJ, et al. An official ATS/ERS/JRS/ALAT statement: idiopathic pulmonary fibrosis: evidence-based guidelines for diagnosis and management. Am J Respir Crit Care Med. 2011;183: 788-824.

12. Idiopathic Pulmonary Fibrosis Clinical Research Network, Raghu G, Anstrom KJ, et al. Prednisone, azathioprine, and N-acetylcysteine for pulmonary fibrosis. N Engl J Med. 2012;366:1968-1977.

13. Maher TM. Pirfenidone in idiopathic pulmonary fibrosis. Drugs Today (Barc). 2010;46:473-482.

14. Gurujeyalakshmi G, Hollinger MA, Giri SN. Pirfenidone inhibits PDGF isoforms in bleomycin hamster model of lung fibrosis at the translational level. Am J Physiol. 1999;276:L311-L318.

15. Iyer SN, Gurujeyalakshmi G, Giri SN. Effects of pirfenidone on transforming growth factor-beta gene expression at the transcriptional level in bleomycin hamster model of lung fibrosis. J Pharmacol Exp Ther. 1999;291:367-373.

16. Iyer SN, Gurujeyalakshmi G, Giri SN. Effects of pirfenidone on procollagen gene expression at the transcriptional level in bleomycin hamster model of lung fibrosis. J Pharmacol Exp Ther. 1999;289:211-218.

17. Oku H, Shimizu T, Kawabata T, et al. Antifibrotic action of pirfenidone and prednisolone: different effects on pulmonary cytokines and growth factors in bleomycin-induced murine pulmonary fibrosis. Eur J Pharmacol. 2008;590:400-408.

18. Azuma A, Nukiwa T, Tsuboi E, et al. Double-blind, placebo-controlled trial of pirfenidone in patients with idiopathic pulmonary fibrosis. $\mathrm{Am}$ J Respir Crit Care Med. 2005;171:1040-1047.
19. Taniguchi H, Ebina M, Kondoh $\mathrm{Y}$, et al. Pirfenidone in idiopathic pulmonary fibrosis. Eur Respir J. 2010;35:821-829.

20. Noble PW, Albera C, Bradford WZ, et al. Pirfenidone in patients with idiopathic pulmonary fibrosis (CAPACITY): two randomised trials. Lancet. 2011;377:1760-1769.

21. Spagnolo P, Del Giovane C, Luppi F, et al. Non-steroid agents for idiopathic pulmonary fibrosis. Cochrane Database Syst Rev. 2010;9: CD003134.

22. Raghu G, Johnson WC, Lockhart D, Mageto Y. Treatment of idiopathic pulmonary fibrosis with a new antifibrotic agent, pirfenidone: results of a prospective, open-label phase II study. Am J Respir Crit Care Med. 1999;159:1061-1069.

23. Hunninghake GW. Antioxidant therapy for idiopathic pulmonary fibrosis. N Engl J Med. 2005;353:2285-2287.

24. Cantin AM, Hubbard RC, Crystal RG. Glutathione deficiency in the epithelial lining fluid of the lower respiratory tract in idiopathic pulmonary fibrosis. Am Rev Respir Dis. 1989;139:370-372.

25. Gillissen A, Nowak D. Characterization of N-acetylcysteine and ambroxol in anti-oxidant therapy. Respir Med. 1998;92:609-623.

26. Das SK, White AC, Fanburg BL. Modulation of transforming growth factor-beta 1 antiproliferative effects on endothelial cells by cysteine, cystine, and N-acetylcysteine. J Clin Invest. 1992;90: $1649-1656$.

27. White AC, Maloney EK, Lee SL, Lanzillo JJ, Fanburg BL. Reduction of endothelial cell related TGF beta activity by thiols. Endothelium. 1999;6:231-239.

28. Zafarullah M, Li WQ, Sylvester J, Ahmad M. Molecular mechanisms of N-acetylcysteine actions. Cell Mol Life Sci. 2003;60:6-20.

29. Meyer A, Buhl R, Magnussen H. The effect of oral N-acetylcysteine on lung glutathione levels in idiopathic pulmonary fibrosis. Eur Respir J. 1994; 7:431-436.

30. Behr J, Maier K, Degenkolb B, Krombach F, Vogelmeier C. Antioxidative and clinical effects of high-dose $\mathrm{N}$-acetylcysteine in fibrosing alveolitis. Adjunctive therapy to maintenance immunosuppression. Am J Respir Crit Care Med. 1997;156:1897-1901.

31. Demedts M, Behr J, Buhl R, et al. High-dose acetylcysteine in idiopathic pulmonary fibrosis. N Engl J Med. 2005;353:2229-2242.

32. Trulock EP, Christie JD, Edwards LB, et al. Registry of the International Society for Heart and Lung Transplantation: twenty-fourth official adult lung and heart-lung transplantation report - 2007. J Heart Lung Transplant. 2007;26:782-795.

33. Orens JB, Estenne M, Arcasoy S, et al. International guidelines for the selection of lung transplant candidates: 2006 update - a consensus report from the Pulmonary Scientific Council of the International Society for Heart and Lung Transplantation. J Heart Lung Transplant. 2006;25: $745-755$.

34. Christie JD, Edwards LB, Kucheryavaya AY, et al. The registry of the international society for heart and lung transplantation: twenty-eighth adult lung and heart-lung transplant report - 2011. J Heart Lung Transplant. 2011;30:1123-1132.

35. Panos RJ, Mortenson RL, Niccoli SA, King TE Jr. Clinical deterioration in patients with idiopathic pulmonary fibrosis: causes and assessment. Am J Med. 1990;88:396-404.

36. Walter N, Collard HR, King TE Jr. Current perspectives on the treatment of idiopathic pulmonary fibrosis. Proc Am Thorac Soc. 2006;3: 330-338.

37. Collard HR, Moore BB, Flaherty KR, et al. Acute exacerbations of idiopathic pulmonary fibrosis. Am J Respir Crit Care Med. 2007;176: 636-643.

38. Kubo H, Nakayama K, Yanai M, et al. Anticoagulant therapy for idiopathic pulmonary fibrosis. Chest. 2005;128:1475-1482.

39. Song JW, Hong SB, Lim CM, Koh Y, Kim DS. Acute exacerbation of idiopathic pulmonary fibrosis: incidence, risk factors and outcome. Eur Respir J. 2011;37:356-363.

40. Churg A, Müller NL, Silva CI, Wright JL. Acute exacerbation (acute lung injury of unknown cause) in UIP and other forms of fibrotic interstitial pneumonias. Am J Surg Pathol. 2007;31:277-284. 
41. Collard HR, Calfee CS, Wolters PJ, et al. Plasma biomarker profiles in acute exacerbation of idiopathic pulmonary fibrosis. Am J Physiol Lung Cell Mol Physiol. 2010;299:L3-L7.

42. Tobin RW, Pope CE 2nd, Pellegrini CA, Emond MJ, Sillery J, Raghu G. Increased prevalence of gastroesophageal reflux in patients with idiopathic pulmonary fibrosis. Am J Respir Crit Care Med. 1998;158: 1804-1808.

43. Raghu G, Freudenberger TD, Yang S, et al. High prevalence of abnormal acid gastro-oesophageal reflux in idiopathic pulmonary fibrosis. Eur Respir J. 2006;27:136-142.

44. Amigoni M, Bellani G, Scanziani M, et al. Lung injury and recovery in a murine model of unilateral acid aspiration: functional, biochemical, and morphologic characterization. Anesthesiology. 2008;108:1037-1046.

45. Moran TJ. Experimental aspiration pneumonia: IV. Inflammatory and reparative changes produced by intratracheal injections of autologous gastric juice and hydrochloric acid. Arch Pathol. 1965;60:122-129.

46. Teabeaut JR 2nd. Aspiration of gastric contents; an experimental study. Am J Pathol. 1952;28:51-67.

47. Greenfield LJ, Singleton RP, McCaffree DR, Coalson JJ. Pulmonary effects of experimental graded aspiration of hydrochloric acid. Ann Surg. 1969;170:74-86.

48. Kwan M, Xu YD, Raghu G, Khalil N. Acid treatment of normal rat lungs releases transforming growth factor-beta1 (TGF-beta1) and increases connective tissue synthesis. Proceedings of the American Thoracic Society (PATS). Am J Respir Crit Care Med. 2007;175:A967.

49. Perng DW, Chang KT, Su KC, et al. Exposure of airway epithelium to bile acids associated with gastroesophageal reflux symptoms: a relation to transforming growth factor-beta1 production and fibroblast proliferation. Chest. 2007;132:1548-1556.

50. Tcherakian C, Cottin V, Brillet PY, et al. Progression of idiopathic pulmonary fibrosis: lessons from asymmetrical disease. Thorax. 2011; 66:226-231.

51. Lee JS, Ryu JH, Elicker BM, et al. Gastroesophageal reflux therapy is associated with longer survival in patients with idiopathic pulmonary fibrosis. Am J Respir Crit Care Med. 2011;184:1390-1394.

52. Raghu G, Yang ST, Spada C, Hayes J, Pellegrini CA. Sole treatment of acid gastroesophageal reflux in idiopathic pulmonary fibrosis: a case series. Chest. 2006;129:794-800.

53. Linden PA, Gilbert RJ, Yeap BY, et al. Laparoscopic fundoplication in patients with end-stage lung disease awaiting transplantation. J Thorac Cardiovasc Surg. 2006;131:438-446.

54. Maher TM. Idiopathic pulmonary fibrosis: pathobiology of novel approaches to treatment. Clin Chest Med. 2012;33:69-83.

55. Cox M, Nelson DR. Lehninger: Principles of Biochemistry. 5th ed. New York: WH Freeman; 2008

56. Daniels CE, Wilkes MC, Edens M, et al. Imatinib mesylate inhibits the profibrogenic activity of TGF-beta and prevents bleomycin-mediated lung fibrosis. J Clin Invest. 2004;114:1308-1316.

57. Aono $\mathrm{Y}$, Nishioka $\mathrm{Y}$, Inayama $\mathrm{M}$, et al. Imatinib as a novel antifibrotic agent in bleomycin-induced pulmonary fibrosis in mice. Am J Respir Crit Care Med. 2005;171:1279-1285.

58. Vuorinen K, Gao F, Oury TD, Kinnula VL, Myllärniemi M. Imatinib mesylate inhibits fibrogenesis in asbestos-induced interstitial pneumonia. Exp Lung Res. 2007;33:357-373.

59. Daniels CE, Lasky JA, Limper AH, et al. Imatinib treatment for idiopathic pulmonary fibrosis: randomized placebo-controlled trial results. Am J Respir Crit Care Med. 2010;181:604-610.

60. Allen JT, Spiteri MA. Growth factors in idiopathic pulmonary fibrosis: relative roles. Respir Res. 2002;3:13.

61. Chaudhary NI, Roth GJ, Hilberg F, et al. Inhibition of PDGF, VEGF and FGF signalling attenuates fibrosis. Eur Respir J. 2007;29:976-985.

62. Richeldi L, Costabel U, Selman M, et al. Efficacy of a tyrosine kinase inhibitor in idiopathic pulmonary fibrosis. $N$ Engl J Med. 2011;365: 1079-1087.

63. Richter A, Puddicombe SM, Lordan JL, et al. The contribution of interleukin (IL)-4 and IL-13 to the epithelial-mesenchymal trophic unit in asthma. Am J Respir Cell Mol Biol. 2001;25:385-391.
64. Phipps S, Ying S, Wangoo A, Ong YE, Levi-Schaffer F, Kay AB. The relationship between allergen-induced tissue eosinophilia and markers of repair and remodelling in human atopic skin. J Immunol. 2002;169: 4604-4612.

65. Hancock A, Armstrong L, Gama R, Millar A. Production of interleukin 13 by alveolar macrophages from normal and fibrotic lung. Am J Respir Cell Mol Biol. 1998;18:60-65.

66. Zhu Z, Homer RJ, Wang Z, et al. Pulmonary expression of interleukin-13 causes inflammation, mucus hypersecretion, subepithelial fibrosis, physiologic abnormalities, and eotaxin production. $J$ Clin Invest. 1999;103:779-788.

67. Belperio JA, Dy M, Burdick MD, et al. Interaction of IL-13 and C10 in the pathogenesis of bleomycin-induced pulmonary fibrosis. Am J Respir Cell Mol Biol. 2002;27:419-427.

68. Rose CE Jr, Sung SS, Fu SM. Significant involvement of CCL2 (MCP-1) in inflammatory disorders of the lung. Microcirculation. 2003;10: 273-288.

69. Moore BB, Kolodsick JE, Thannickal VJ, et al. CCR2-mediated recruitment of fibrocytes to the alveolar space after fibrotic injury. Am J Pathol. 2005;166:675-684.

70. Baran CP, Opalek JM, McMaken S, et al. Important roles for macrophage colony-stimulating factor, $\mathrm{CC}$ chemokine ligand 2, and mononuclear phagocytes in the pathogenesis of pulmonary fibrosis. Am J Respir Crit Care Med. 2007;176:78-89.

71. Moore BB, Paine R 3rd, Christensen PJ, et al. Protection from pulmonary fibrosis in the absence of CCR2 signalling. I Immunol. 2001;167:4368-4377.

72. Gharaee-Kermani M, McCullumsmith RE, Charo IF, Kunkel SL, Phan SH. CC-chemokine receptor 2 required for bleomycin-induced pulmonary fibrosis. Cytokine. 2003;24:266-276.

73. Bartram U, Speer CP. The role of transforming growth factor beta in lung development and disease. Chest. 2004;125:754-765.

74. Corrin B, Butcher D, McAnulty BJ, et al. Immunohistochemical localization of transforming growth factor-beta 1 in the lungs of patients with systemic sclerosis, cryptogenic fibrosing alveolitis and other lung disorders. Histopathology. 1994;24:145-150.

75. Kapanci Y, Desmouliere A, Pache JC, Redard M, Gabbiani G. Cytoskeletal protein modulation in pulmonary alveolar myofibroblasts during idiopathic pulmonary fibrosis. Possible role of transforming growth factor beta and tumor necrosis factor alpha. Am J Respir Crit Care Med. 1995;152:2163-2169.

76. Broekelmann TJ, Limper AH, Colby TV, McDonald JA. Transforming growth factor beta 1 is present at sites of extracellular matrix gene expression in human pulmonary fibrosis. Proc Natl Acad Sci U S A. 1991;88:6642-6646.

77. Blobe GC, Schiemann WP, Lodish HF. Role of transforming growth factor beta in human disease. N Engl J Med. 2000;342:1350-1358.

78. Postlethwaite AE, Keski-Oja J, Moses HL, Kang AH. Stimulation of the chemotactic migration of human fibroblasts by transforming growth factor beta. $J$ Exp Med. 1987;165:251-256.

79. Desmoulière A, Geinoz A, Gabbiani F, Gabbiani G. Transforming growth factor-beta 1 induces alpha-smooth muscle actin expression in granulation tissue myofibroblasts and in quiescent and growing cultured fibroblasts. J Cell Biol. 1993;122:103-111.

80. Willis BC, Liebler JM, Luby-Phelps K, et al. Induction of epithelialmesenchymal transition in alveolar epithelial cells by transforming growth factor-beta1: potential role in idiopathic pulmonary fibrosis. Am J Pathol. 2005;166:1321-1332.

81. Zhang HY, Phan SH. Inhibition of myofibroblast apoptosis by transforming growth factor beta(1). Am J Respir Cell Mol Biol. 1999;21: 658-665.

82. Phan SH. The myofibroblast in pulmonary fibrosis. Chest. 2002;122: 286S-289S

83. Selman M, Ruiz V, Cabrera S, et al. TIMP-1, $-2,-3$, and -4 in idiopathic pulmonary fibrosis. A prevailing nondegradative lung microenvironment? Am J Physiol Lung Cell Mol Physiol. 2000;279: L562-L574. 
84. García-Alvarez J, Ramirez R, Checa M, et al. Tissue inhibitor of metalloproteinase-3 is up-regulated by transforming growth factorbeta 1 in vitro and expressed in fibroblastic foci in vivo in idiopathic pulmonary fibrosis. Exp Lung Res. 2006;32:201-214.

85. Kulkarni AB, Huh CG, Becker D, et al. Transforming growth factor $\beta 1$ null mutation in mice causes excessive inflammatory response and early death. Proc Natl Acad Sci U S A. 1993;90:770-774.

86. Annes JP, Munger JS, Rifkin DB. Making sense of latent TGFbeta activation. J Cell Sci. 2003;116:217-224.

87. Breuss JM, Gallo J, DeLisser HM, et al. Expression of the $\beta 6$ subunit in development, neoplasia and tissue repair suggests a role in epithelial remodeling. J Cell Sci. 1995;108:2241-2251.

88. Horan GS, Wood S, Ona V, et al. Partial inhibition of integrin alpha(v) beta6 prevents pulmonary fibrosis without exacerbating inflammation. Am J Respir Crit Care Med. 2008;177:56-65.

89. Munger JS, Huang X, Kawakatsu H, et al. The integrin alpha v beta 6 binds and activates latent TGF beta 1: a mechanism for regulating pulmonary inflammation and fibrosis. Cell. 1999;96:319-328.

90. Puthawala K, Hadjiangelis N, Jacoby SC, et al. Inhibition of integrin alpha(v)beta6, an activator of latent transforming growth factor-beta, prevents radiation-induced lung fibrosis. Am J Respir Crit Care Med. 2008; 177:82-90

91. Bonniaud P, Margetts PJ, Ask K, Flanders K, Gauldie J, Kolb M. TGFbeta and Smad3 signaling link inflammation to chronic fibrogenesis. J Immunol. 2005;175:5390-5395.

92. Higashiyama H, Yoshimoto D, Kaise T, et al. Inhibition of activin receptor-like kinase 5 attenuates bleomycin-induced pulmonary fibrosis. Exp Mol Pathol. 2007;83:39-46.

93. Rucker RB, Murray J. Cross-linking amino acids in collagen and elastin. Am J Clin Nutr. 1978;31:1221-1236.

94. Yamauchi M, Shiiba M. Lysine hydroxylation and cross-linking of collagen. Methods Mol Biol. 2008;446:95-108.

95. Akiri G, Sabo E, Dafni H, et al. Lysyl oxidase-related protein-1 promotes tumor fibrosis and tumor progression in vivo. Cancer Res. 2003;63:1657-1666.

96. Barry-Hamilton V, Spangler R, Marshall D, et al. Allosteric inhibition of lysyl oxidase-like-2 impedes the development of a pathologic microenvironment. Nat Med. 2010;16:1009-1017.

97. Vadasz Z, Kessler O, Akiri G, et al. Abnormal deposition of collagen around hepatocytes in Wilson's disease is associated with hepatocyte specific expression of lysyl oxidase and lysyl oxidase like protein-2. J Hepatol. 2005;43:499-507.

98. Saito H, Papaconstantinou J, Sato H, Goldstein S. Regulation of a novel gene encoding a lysyl oxidase-related protein in cellular adhesion and senescence. J Biol Chem. 1997;272:8157-8160.

99. Pascal T, Debacq-Chainiaux F, Chrétien A, et al. Comparison of replicative senescence and stress-induced premature senescence combining differential display and low-density DNA arrays. FEBS Lett. 2005;579:3651-3659.

100. Lewis BP, Burge CB, Bartel DP. Conserved seed pairing, often flanked by adenosines, indicates that thousands of human genes are microRNA targets. Cell. 2005;120:15-20.

101. Lau NC, Lim LP, Weinstein EG, Bartel DP. An abundant class of tiny RNAs with probable regulatory roles in Caenorhabditis elegans. Science. 2001;294:858-862.

102. Galasso M, Elena Sana M, Volinia S. Non-coding RNAs: a key to future personalized molecular therapy? Genome Med. 2010;2:12.

103. Grosshans H, Filipowicz W. Molecular biology: the expanding world of small RNAs. Nature. 2008;451:414-416.

104. Tsai LM, Yu D. MicroRNAs in common diseases and potential therapeutic applications. Clin Exp Pharmacol Physiol. 2010;37:102-107.

105. Pandit KV, Milosevic J, Kaminski N. MicroRNAs in idiopathic pulmonary fibrosis. Transl Res. 2011;157:191-199.

106. Fabbri M, Garzon R, Cimmino A, et al. MicroRNA-29 family reverts aberrant methylation in lung cancer by targeting DNA methyltransferases 3A and 3B. Proc Natl Acad Sci U S A. 2007;104: 15805-15810.
107. Liu G, Friggeri A, Yang Y, Milosevic J, et al. miR-21 mediates fibrogenic activation of pulmonary fibroblasts and lung fibrosis. $J$ Exp Med. 2010;207:1589-1597.

108. Cushing L, Kuang PP, Qian J, et al. miR-29 is a major regulator of genes associated with pulmonary fibrosis. Am J Respir Cell Mol Biol. 2011;45:287-294.

109. Oak SR, Murray L, Herath A, et al. A micro RNA processing defect in rapidly progressing idiopathic pulmonary fibrosis. PLoS One. 2011;6: e21253.

110. Krützfeldt J, Rajewsky N, Braich R, et al. Silencing of microRNAs in vivo with 'antagomirs'. Nature. 2005;438:685-689.

111. Mora AL, Woods CR, Garcia A, et al. Lung infection with gammaherpesvirus induces progressive pulmonary fibrosis in Th2-biased mice. Am J Physiol Lung Cell Mol Physiol. 2005;289:L711-L721.

112. Mora AL, Torres-González E, Rojas M, et al. Control of virus reactivation arrests pulmonary herpesvirus-induced fibrosis in IFNgamma receptor-deficient mice. Am J Respir Crit Care Med. 2007;175: 1139-1150.

113. Méndez-Samperio P, Hernandez M, Ayala HE. Induction of transforming growth factor-beta 1 production in human cells by herpes simplex virus. J Interferon Cytokine Res. 2000;20:273-280.

114. Malizia AP, Keating DT, Smith SM, Walls D, Doran PP, Egan JJ. Alveolar epithelial cell injury with Epstein-Barr virus upregulates TGF-betal expression. Am J Physiol Lung Cell Mol Physiol. 2008;295: L451-L460.

115. Stoolman JS, Vannella KM, Coomes SM, et al. Latent infection by \}herpesvirus stimulates profibrotic mediator release from multiple cell types. Am J Physiol Lung Cell Mol Physiol. 2011;300:L274-L285.

116. Yonemaru M, Kasuga I, Kusumoto H, et al. Elevation of antibodies to cytomegalovirus and other herpes viruses in pulmonary fibrosis. Eur Respir J. 1997;10:2040-2045.

117. Tang YW, Johnson JE, Browning PJ, et al. Herpesvirus DNA is consistently detected in lungs of patients with idiopathic pulmonary fibrosis. J Clin Microbiol. 2003;41:2633-2640.

118. Magro CM, Allen J, Pope-Harman A, et al. The role of microvascular injury in the evolution of idiopathic pulmonary fibrosis. Am J Clin Pathol. 2003;119:556-567.

119. Vergnon JM, Vincent M, de Thé G, Mornex JF, Weynants P, Brune J. Cryptogenic fibrosing alveolitis and Epstein-Barr virus: an association? Lancet. 1984;2:768-771.

120. Egan JJ, Stewart JP, Hasleton PS, Arrand JR, Carroll KB, Woodcock AA. Epstein-Barr virus replication within pulmonary epithelial cells in cryptogenic fibrosing alveolitis. Thorax. 1995;50:1234-1239.

121. Stewart JP, Egan JJ, Ross AJ, et al. The detection of Epstein-Barr virus DNA in lung tissue from patients with idiopathic pulmonary fibrosis. Am J Respir Crit Care Med. 1999;159:1336-1341.

122. Tsukamoto K, Hayakawa H, Sato A, Chida K, Nakamura H, Miura K. Involvement of Epstein-Barr virus latent membrane protein 1 in disease progression in patients with idiopathic pulmonary fibrosis. Thorax. 2000;55:958-961.

123. Manika K, Alexiou-Daniel S, Papakosta D, et al. Epstein-Barr virus DNA in bronchoalveolar lavage fluid from patients with idiopathic pulmonary fibrosis. Sarcoidosis Vasc Diffuse Lung Dis. 2007;24: 134-140.

124. Vannella KM, Luckhardt TR, Wilke CA, van Dyk LF, Toews GB, Moore BB. Latent herpesvirus infection augments experimental pulmonary fibrosis. Am J Respir Crit Care Med. 2010;181: 465-477.

125. Eliopoulos AG, Young LS. LMP1structure and signal transduction. Semin Cancer Biol. 2001;11:435-444.

126. Sides MD, Klingsberg RC, Shan B, et al. The Epstein-Barr virus latent membrane protein 1 and transforming growth factor $-\beta 1$ synergistically induce epithelial - mesenchymal transition in lung epithelial cells. Am J Respir Cell Mol Biol. 2011;44:852-862.

127. Egan JJ, Adamali HI, Lok SS, Stewart JP, Woodcock AA. Ganciclovir antiviral therapy in advanced idiopathic pulmonary fibrosis: an open pilot study. Pulm Med. 2011;2011:240805. 


\section{Publish your work in this journal}

Drug Design, Development and Therapy is an international, peerreviewed open-access journal that spans the spectrum of drug design and development through to clinical applications. Clinical outcomes, patient safety, and programs for the development and effective, safe, and sustained use of medicines are a feature of the journal, which

has also been accepted for indexing on PubMed Central. The manuscript management system is completely online and includes a very quick and fair peer-review system, which is all easy to use. Visit http://www.dovepress.com/testimonials.php to read real quotes from published authors.

Submit your manuscript here: http://www.dovepress.com/drug-design-development-and-therapy-journal 